\title{
INNOVATION NETWORKING, KNOWLEDGE TRANSDISCIPLINARY SPACES
}

\author{
Professor Ioan Gh. Pop PhD, \\ Emanuel University of Oradea, Romania \\ E-mail: ioan.pop@emanuel.ro \\ Associate Professor Ioan S. Fotea PhD, \\ Emanuel University of Oradea, Romania \\ E-mail: ioan.fotea@emanuel.ro \\ Silvia L. Fotea \\ Bucharest University of Economic Studies, Romania \\ E-mail: silvia.fotea@gmail.com
}

(Received: April 2018; Accepted: June 2018)

\begin{abstract}
In this paper a novel approach on knowledge integration in presented in the context of the knowledge-based society/economy (KBS/E). What this paper brings new is the transdisciplinary integrative approach of the knowledge through the "conceptual knowledge space" as a potentiality, and the "practical transdisciplinary knowledge space", as actuality, with the transition between them through the included middle. Are introduced some of the most important practical educational environmental transdisciplinary conceptual and applied spaces, as innovative groundbreaking clusters that foster the origination, transfer and implementation of knowledge in the process of achieving sustainable development of the continuously integrative society. The University is considered the most appropriate space for this transdisciplinary approach of knowledge achievement, being a natural habitat of the synergistic integration of education, research and industry, and with its adaptability and adequateness in the knowledge economy space. University should become an open space in a reconfiguration in a integration of a highrequired degree with breadth profile competence in the integrated fields of different disciplines, with the need to have a depth profile of the knowledge in research on particular cognitive field. A new redefined mission of university by collaborating with industry should be linked to a redefinition of the role of the research in universities in the knowledge based society/economy.

Key words: knowledge-based economy/society (KBS/E), knowledge integrating management (KIM), synergistic integration of education, transdisciplinary conceptual and practical knowledge centers, groundbreaking clusters;
\end{abstract}

JEL CLASSIFICATION: D83

DE GRUYTER Studia Universitatis "Vasile Goldis" Arad. Economics Series Vol 28 Issue 2/2018

OPEN ISSN: 1584-2339; (online) ISSN: 2285-3065

Web: publicatii.uvvg.ro/index.php/studiaeconomia. Pages $86-106$ 


\section{Introduction}

The world community is involved in a continuous process to solve the necessity of the development and assumption of the common world's economic principles and rules in the reality of the knowledge-based society/economy (KBS/E) (Pop \& Mătieş, 2011; Adamsson, 2007). The difficulties in solving this problem reside in high complexity of the world economy development and the multi-factorial process. To solve such kind of problems means to go "beyond that is known", in the context of the existence of some new specific scientific methodologies as multi (pluri) disciplinarity, inter(cross) disciplinarity, and transdisciplinarity (Pop \& Mătieş, 2011; Nicolescu, 2006; Pop, 2011; Ertas, 2010). To solve problems of the global business environment demands to change or to underlie contextually the basic issues of the current understanding of the integrative knowledge (Brazell et al, 2005). From this perspective knowledge represents a very popular issue with the knowledge management as the most in vogue subject of the day, as well (Nonaka \& Takeuchi, 1995; Jashapara, 2011). For the informergic society (intention acting to incorporate information into mattergy to obtain intelligent products, technologies and systems), as the knowledge based society/economy (KBS/E) can be identified (Pop, 2011; Pop \& Maties, 2011). The posed question represents the way the advanced knowledge is obtained, shared and utilized (Zeleny, 1987; Roux, 2006; Pop et al, 2015). Referring to the state of knowing, the knowledge based society/economy (KBS/E) could be better analysed using the semiophysical approach with the seven questions (habits) knowledge paradigm (Pop \& Mătieş, 2011; Pop, 2011; Gitt, 1997; Covey, 2003). Are identified three synergisticgenerative sequences: space wise (,think globally and act locally”) - spatial participative sequence (where, who, with whom), time wise ("think long-term and act now") - temporal connective sequence (when, who, with whom), and act wise ("be aware that your act produces consequences globally and your thoughts are rooted locally") - actionable interactive sequence, (who, with whom, what, how and why) (Pop, 2011; Pop, 2008; Hall, 1959; Slaus, 2003). The contextual communication model works with the "WHW (What-How-Why)" paradigm from data and information to the advanced knowledge as expertise by passing through sustainable integrative all life learning sequence (Pop \& Maties, 2011; Pop et al, 2015; Buckley, 2000).

\section{Transdisciplinarity and informergic integration of knowledge}

\subsection{Epistemological distance as parameter of the advanced knowledge}

It is critical to comprehend the complexity of the new kind of society based on advanced knowledge as a natural part of the world as a whole (Nicolescu, 2006), working in an integrative informergic pattern (informaction as intentional 
Pop, I. Gh., Fotea, I. S., Fotea, S. L. (2018)

Innovation networking, knowledge transdisciplinary spaces

information embedded in mattergy as energy and matter) of what is the rational "by doing" and relational "by being" approach (Pop, 2011; Pop \& Maties, 2011). The understanding of the needs, as well as goods and benefits with which these needs can be satisfied, the rules for the goods production, exchange and distribution all over the planet should result from the awareness that people are natural components of this one unique world (Nicolescu, 2008). The new framework of the knowledge based society/economy (KBS/E) asks an alternative approach, introduced and defined in this context, as complementary way, having their own principles and limits of applicability (Pop, 2011). In knowledge theory, part of the disciplines are considered closer together, while others are deemed more distant, with a very peculiar epistemological distance between them, determined and measured through space, time and action (Pop \& Mătieş, 2011). A discipline, as a depth approach, is a narrow branch of knowledge, instruction, or learning which is held together by a shared epistemology, as assumptions about the nature of knowledge, but separated by the distinct barriers, methodologies working as acceptable ways of generating or accumulating knowledge in a specific way (Nicolescu, 2006; Pop, 2011). Based on the epistemological distance proximity, disciplines cluster into groups, or knowledge subsystems such as natural sciences, social sciences, humanities, besides others, some of them using quantitative or/and qualitative specific methods (Max Neef, 2005; Pop, 2011; Cook \& Brown, 1999).

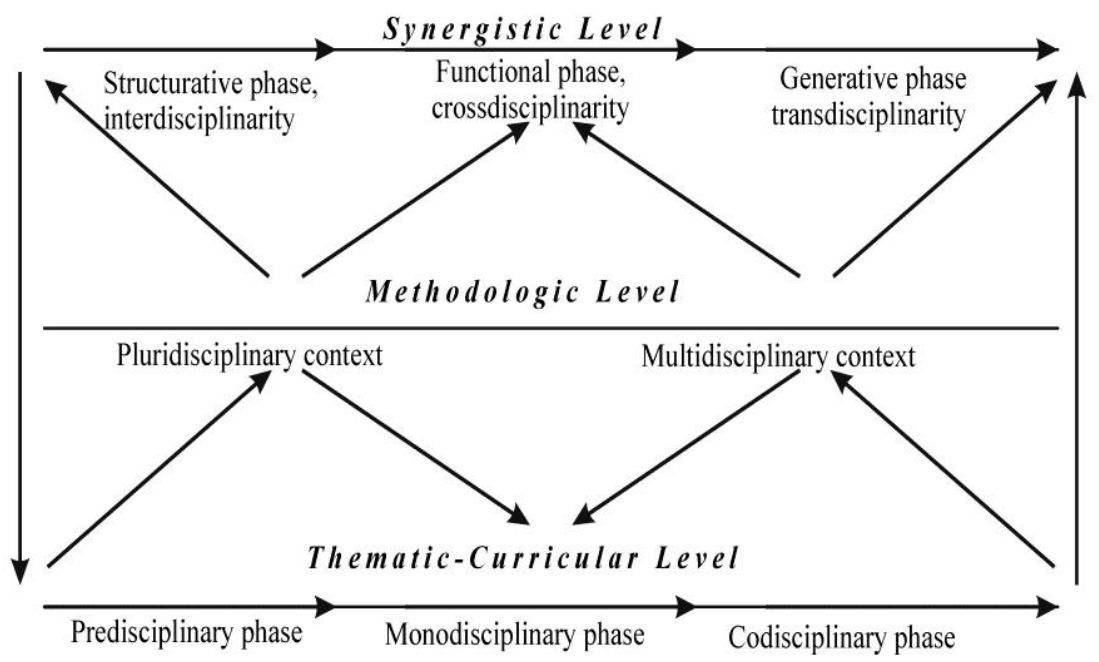

Figure 1. The multi-disciplinary thinking approach of the knowledge integration Source: Author's view 
Disciplines that cluster in the same knowledge subsystems are closer to each other, those belonging to different subsystems being further away from each other, the chance of overlapping of the different specific knowledge spheres being determined by the epistemological distance (Pop \& Maties, 2011). The disciplinary level of knowledge works at the thematic-curricular level in a context that can be predisciplinary, mono-disciplinary or codisciplinary. On the other hand, the professional programs and research groups generally operate on a multi/pluri disciplinary model (methodological level), thus being more than disciplines. In some instances they could bridge across knowledge subsystems functioning at the synergistic level as a multiple disciplinary thinking perspective of the knowledge integration (figure 1) (Pop \& Mătieş, 2011; Jashapara, 2011).

When combining more separated disciplines, with epistemologically differences, these offer new understandings for a complex kind of problems or issues than disciplines that share similar epistemological assumptions can do. Alternative methods and perspectives are provided by the differences between disciplines, thus making possible to see multiple facets of the reality in a complex context, which leads to the cognitive process of appearing of new ideas and knowledge perspectives. Disparate disciplines bring different perspective, which increases the probability of tackling complex problems with success (Palmer, 1978; Pop \& Mătieş, 2011). Transdisciplinarity explains better than existing models of the emergence of the new epistemic teaching-learning paradigm, that of the synergistic generative identity, as a new sustainable integrative all life learning (lifelong learning, wide life learning, learning for life) way of achieving advanced knowledge as expertise (wisdom-top down, and skills-bottom up) (Pop, 2011).

\subsection{Knowledge spectrum. A transdisciplinary perspective}

Understanding in real life the knowledge process it is required going further than the local level, thus looking at the distribution into wider networks. Only practices connect contextually things, people, and events that are distant and only partially congruent, because they allow the coexistence of old and new, being able to deal with change and disorder while explaining persistence and order (Nicolini et al. 2003). We consider that knowledge could be portrayed in a large spectrum from completely tacit, like semiconscious and unconscious knowledge, as hands-on knowledge (Jashapara, 2011; Nonaka \& Takeuchi, 1994; Polanyi, 1997) to completely explicit, accessible to people, represented as hands-off knowledge, passing through a transitional hands-in state (Pop \& Mătieş, 2011; Pop, 2011) (Figure 2). 


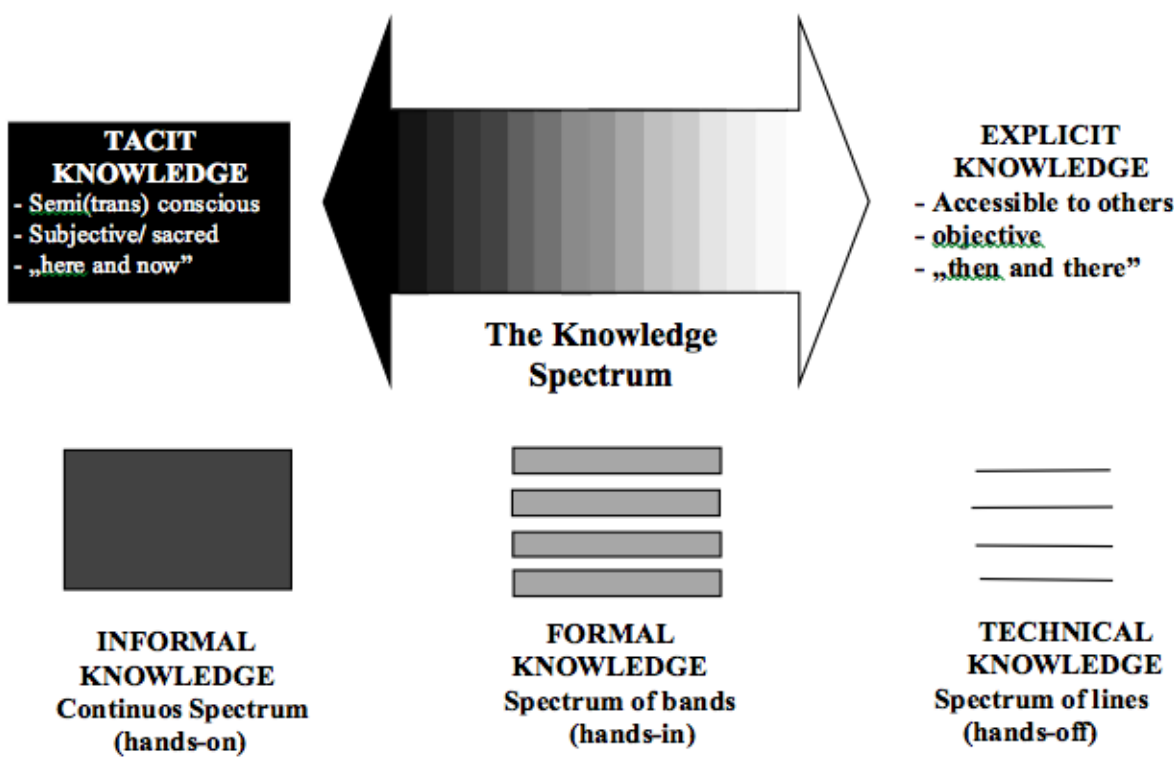

Figure 2. The transdisciplinary knowledge spectrum

Source: Pop, 2011

Knowledge is considered as hands-on large spectrum, with a continuum shape at one side, the almost completely tacit, as semiconscious and unconscious knowledge (Nonaka \& Takeuchi, 1994; Polanyi, 1997). The close to completely explicit knowledge, which is understandable by other people that originate it is shown as a line on the knowledge spectrum. Explicit elements are objective, rational and created "then and there" (top-down level), tacit elements being subjective, experiential and created "here and now" (bottom-up level) (Leonard \& Sensiper, 1998; Pop \& Maties, 2011).

One should study the methods of quantifying, capturing, coding and storing knowledge, a primary characteristic in managing tacit knowledge lying in its conversion in a easy, traditional handling format, which can be done through the knowledge integration process, which is of transdisciplinary nature. The process starts with passive knowledge (hands-on), goes through passive-active stage to become active knowledge (hand-off). Selecting the message to be communicated (know-what) is different to the way the message is coded and transmitted (knowhow), the former having an explicit nature and the latter an implicit one (Brown \& Duguid, 1991; Pop, 2008; Pop, 2011). Thus, procedures are known as a codified 
form of know-how that guide people in how to perform a task. Organizational knowledge constitutes an essential competency, being more than "know-what", requiring the more ambiguous "know-how" - the particular ability to put knowwhat into practice as know-how (Hildreth et al, 2000; Gomes et al, 2003). In order to provide an adequate environment to create, nurture and sustain the knowledge through a specific networking as interaction with others, the Communities of Practice (CoPs) are considered to be emergent and creative groups working as synergistic/generative centers, where transactive knowledge (knowing what you know) and resource knowledge (knowing who knows what) focus especially on the organizational environment (Wenger \& Snyder, 2000; Hildreth \& Kimble, 2004; Hildreth et al, 2000). On the other side, it would be possible to take the community of practice view of entrepreneurial learning in family businesses, a synergistic/generative transdisciplinary pattern working as a specific knowledge space as creative innovation (Fotea et al., 2012a). A paradigm shift from the sequential to simultaneous way of knowledge process, to achieve this objective, is required for an integrative educational approach that seeks to develop systemic synergistic-generative thinking learners/teachers, methodologies and specific technics, as well (Pop \& Maties, 2011). To develop knowledge through interaction with others in a specific context where knowledge is created, nurtured and sustained, people need to be provided with an adequate environment as are the communities of practice (Wenger \& Snyder, 2000; Hildreth \& Kimble, 2004). In this way, it is opening a new perspective with greater possibility to achieve, to store, and to use knowledge, with concepts that can be developed more efficiently, the communications with other spheres of knowledge being improved, the major goals in the field of the new economy being oriented to the client and market satisfaction as well (Harashima, 2005; Montaud, 2008). An adequate environment is required to produce knowledge via interaction with other people, which enables them to create, nurture and sustain it (Wenger \& Snyder, 2000; Hildreth \& Kimble, 2004). In such a context, there is a transactive knowledge as a self-knowledge of an organization (knowing what you know) and resource knowledge (knowing who knows what), which are focusing on the knowledge of the organizational environment (knowing who with whom knows how and why) (Hildreth et al, 2000).

\subsection{Knowledge integration management and DIMLAK model}

Training and education are shaped by the transdisciplinary approach in the knowledge based-society/economy (KBS/E), representing a prerequisite in the new synergistic generative context of education as a guarantee to achieve advanced knowledge (Pop \& Maties, 2011; Pop, 2011; Pop et al, 2015). For this, a new 
Pop, I. Gh., Fotea, I. S., Fotea, S. L. (2018)

Innovation networking, knowledge transdisciplinary spaces

attitude is necessary, an active participation, flexibility and adequateness to the context, converting problems into opportunities. The transdisciplinary approach demands a change of the attitude of all the actors from the "ivory tower" as a strictly monodisciplinary approach to the position of co-evolutionary development (Nicolescu, 2006), providing the opportunity for fundamental changes in the socioeconomic relationships. The problem definition is often more important than its solution, the analysis of the old problems from the new viewpoint demanding creativity, treated as a real scientific success. The transdisciplinary approach opens new perspectives on its development, incorporating more and more ideas which will be accounted to improve the way to do things and to live in the new context of ever-changing needs and willing of a complex and complicated world, when innovations and technologies should be improved and developed with the rapidly changing times (Mieg, 1996; Nicolescu, 1996; Jack \& Sterian, 2002; Pop \& Mătieş, 2009). Such a sequence represents an emergent continuum, because the progression of data to information and then to knowledge does not occur in discrete stages of developing knowledge. As understanding develops, the continuum is more expressive, making it possible to have partial understanding of the relations that represent information, of the patterns representing knowledge, and of the principles, the foundation of a good expertise as wisdom and skills, as advanced knowledge (KBS/E) (Zelenyi, 1987; Pop et al, 2015; Hugos \& Hulitzky, 2011). A very important aspect in the knowledge integration management (KIM) is the integrative chain of knowledge by achievement, sharing and implementing process in the new transdisciplinary DIMLAK knowledge heterarchical-hierarchic flow (Pop et al, 2015) (see figure 3), as follows: (a) Data (D), as statistical approach; (b) Information (I), as syntactic way to relate descriptions, definitions, or perspectives; (c) Synergistic Contextual Message (M), as semantics in order to give significance in a synergistic context; (d) Sustainable integrative All life Learning $(L)$, as pragmatic pattern comprising strategy, practice, method, or approach, and (e) Advanced Knowledge (AK), as apobetics by embodying principle, insight, moral, or archetype, to attend the desired level of Expertise (Wisdom as top-down perspective, and Skills as bottom-up perspective), to achieve the Truth (Pop, 2011; Gitt, 1997; Pop et al, 2015). 


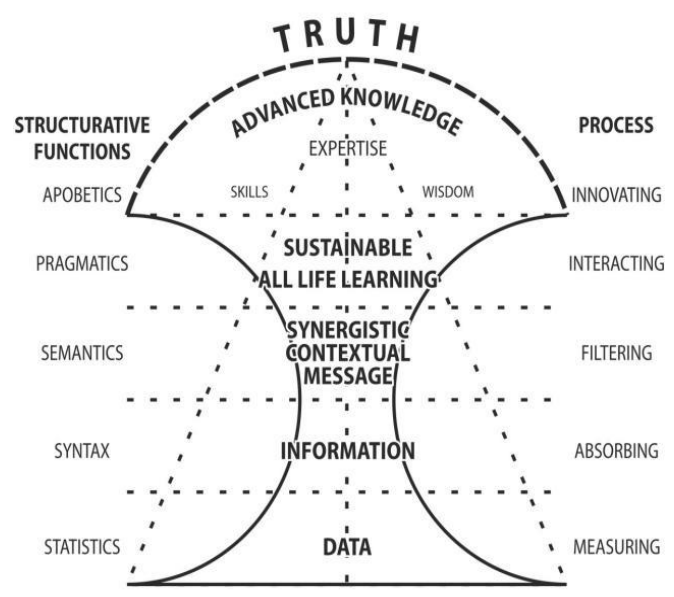

Figure 3. The DIMLAK Transdisciplinary Knowledge Integration Model Source: Pop et al., 2015

\section{Innovation networking, knowledge transdisciplinary spaces}

\subsection{Transdisciplinary Education and the Knowledge Conceptual Spaces}

To maintain competitiveness, companies must design and manufacture their products using new technologies, to be able to rapidly react to change, for competitive product properties and reduced product cycles, connected inherently with a new kind of "sustainable integrative all life learning system" (long life learning, wide life learning and learning for life) (Montaud, 2008; Pop, 2011). Soon, the informergic knowledge will be increasingly oriented on safety, reliability and affordability, using computers to build smart products and technology in an efficient, productive and controlled manner (Jack \& Sterian, 2002; Tुundrea, 2009; Hugos \& Hulitzky, 2011; Warfield, 2007). The proposed integrative models demonstrate that the informergy is a transdisciplinary way of the knowledge integrative process in the knowledge-based society/economy (KBS/E) (Pop 2011), putting together the rational "by doing" with relational "by being" (Pop \& Maties 2011; Pop, 2011). The transdisciplinary knowledge search window is working complementarily, with the top-down and bottom-up levels of knowledge, as a new research methodology (Pop, 2009a). The teacher as a mentor is considered a topdown approach, while the disciples a bottom-up one. The ranks of authority of the teacher and the disciples interact alternatively in a symmetrical and complementary way, depending on the synergistic context, in order to build bridges, avoid conflicts, overpass or even cancel barriers, working and living together, as human 
Pop, I. Gh., Fotea, I. S., Fotea, S. L. (2018)

Innovation networking, knowledge transdisciplinary spaces

beings in a permanent interaction with intelligent systems, technologies and products (Pop, 2011).

In the $\mathrm{KBS} / \mathrm{E}$ context, the new transdisciplinary perspective on the informergic integration of knowledge explains the achieving of knowledge, opening new ways to understand the world, through informergy (informaction as intentional action and information, and mattergy as energy incorporated in matter), as multiple integrative possibilities to understand the way to achieve, transfer and incorporate knowledge. The multiple transdisciplinary paradigm is integrating informergically (informaction integrated in mattergy) the creativity (adequateness and innovation) in action (competition and performance) (Pop \& Pelau, 2017) and authenticity (character and competence) through participation (apprenticeship in communion), in the new methodological concept, the knowledge search window introduced in order to explain the bottom-up/top-down mechanism of the knowledge integration through teaching-learning process in the mechatronic educational paradigm (Pop \& Mătieş, 2008; Pop, 2009). Disciplinary (depth approach) and transdisciplinary research (breadth approach) are not considered as antagonistic approaches, because they are working in the "breadth through depth" complementarily framework, with a new perspective on the knowledge development process.

For a better comprehension of the methods of achieving, transferring and incorporating knowledge in the KBS there are various integrative ways offered by informergy. This can be realized by integrating as two branches of informergic knowledge process, the rational knowledge (by doing) and relational understanding (by being). Proper education to increase awareness of responsibility for environment protection may remain the most effective way. The creativity centers as transdisciplinary knowledge spaces organized as networks (Pop, 2011; Albert \& Lukas, 1999; Fortuin \& Bush, 2010; Doignon \& Falmagne, 1999; Hildreth \& Kimble, 2004) are working for an integrated and continuously integrative society with generative-synergistic correlations with other spheres of knowledge, the major goals in the knowledge based society being focused on the smart products, technologies and systems, with a circular economy for waste as reduce, recycle, reutilize and recombine paradigm (Falkenberg, 2014; Alptekin, 1995; Carryer, 1996) for satisfaction of the client and market, as well (Alptekin et al, 2001; Petts et al, 2008; Pop \& Maties, 2011; Derry \& Fischer, 2005; Nicolescu, 2006; Papoutsidakis et al, 2008; (Fotea et al, 2012a; Wenger, 1998; Albert \& Lukas, 1999). The transdisciplinary knowledge based society/economy, as an informergic world (which integrates informaction as intentionally information into mattergy as energy embedded in material pattern) (Pop \& Maties, 2011) with its integrative rational approach of the knowledge (by doing) and relational approach of living (by being) (Pop, 2011) relies on collaboration, creativity, definition and framing of 
problems, dealing with uncertainty, change, and intelligence distributed across cultures, disciplines, and tools, so teaching/learning programs should foster transdisciplinary competencies to prepare people for meaningful and productive lives in such a world (Derry \& Fischer, 2005); (Nicolescu, 2007). To achieve advanced knowledge, it should be introduced a new generative-significant transdisciplinary education by training the necessary skills in employees to design and maintain smart integrated systems, the new educational principles being focused on the creative concurrent design and development process (Pop, 2009; Carrier, 1996; Novack, 1998). In this sense, one needs to develop in students a knowledge identity (Strathern, 2007), studying in an extensive manner the basic areas of technology with a new integrative sustainable design through vocational educational training systems, integrated as a transdisciplinary knowledge integrative spaces (Pop, 2009; Hargreaves, 2003; Gibbons et al, 1994; Paavola et al, 2004).

Creativity requires exploration and transformation of the "conceptual space" into a living system as a "practical transdisciplinary space", the most important thing being "the identification, stimulation and evaluation of creativity", by transthematic identificators (know what), phenomenological descriptors (know how) and logical explicators (know why) (Pop, 2011), to transform a monodisciplinary space in a transdisciplinary one. As knowledge mainly resides in people relations, not in documents or hard drives, it is critical to identify the spiritual aspect of knowledge, recognized through "by being" syntagma of the informergical integrative paradigm (Reason, 1998; Pop, 2009b). Transdisciplinarity - as rational "by doing", and relational "by being" approach of knowledge achievement - is built on a process which enables employees for a better use, questioning, integration, reconfiguring, adapting or rejecting of information (Nicolescu, 1996; Pop et al, 2015), that allows them to work as a teaching conceptual space of knowledge similar to a factory (Lamancusa et al, 1997; Quinsee \& Hurst, 2005). Thus new bridges that appear between disciplines can be explained as a step by step way through codisciplinary connection, multi(pluri) disciplinary combination, inter(cross) disciplinary overlap and transdisciplinary synergistic synthesis (figure 1) (Bernstein, 2015; Pop \& Maties, 2011). The equilibrium between the outside (with its extrinsic active knowledge aspect) of the person, and the inside (with the intrinsic reactive knowledge aspects) is the basis of the transdisciplinary approach on knowledge.

The formulation of original opinions, rational choice of options, problem solving, debating ideas and teaching beyond rigid academic procedures are some prerequisites of the informergic education designed with a transdisciplinary approach (Pop, 2011; Nicolescu, 2006). Thus, by using simulations in classrooms 
Pop, I. Gh., Fotea, I. S., Fotea, S. L. (2018)

Innovation networking, knowledge transdisciplinary spaces

alone, one cannot replace real experiences, therefore new tools like design, modelling, prototyping are necessary for a comprehensive education (Carrier, 1996; Pop, 2011). The traditional approach, complemented with a more innovative approach help individuals develop and be creative, thus exploring a conceptual structure going beyond them, in a transdisciplinary way, making them able to manage, recognize and articulate new structures which go beyond existing ones (Nicolescu, 2008). Creative systems are able to discern original ideas, perform efficient explorations with novel search strategies to move from one condition to another. The transdisciplinary KBS/E, as an informergic world (which integrates informaction as intentionally information into mattergy as energy embedded in material pattern) (Pop \& Maties, 2011; Pop, 2011) require abilities to better collaborate, identify and define problems, deals with risk, change so teaching/learning programs should nurture competencies that are transdisciplinary in nature in order to prepare individuals for meaningful and productive life experiences.

All these are working for a sustainable development of an integrated and continuously integrative society, to achieve, transfer and implement informergical knowledge, being a future configuration of the transdisciplinary knowledge spaces. These are: transdisciplinary knowledge spaces (TKS) (Petts et al, 2008); (Doignon \& Falmagne, 1999; Albert \& Lukas, 1999), in different ways: intelligent (smart) products, technologies and systems (Alptekin, 1995; Carryer, 1996; Pop, 2011; Browning et al, 2002), eco-efficient products (Falkenberg, 2014), teaching factories (Alptekin et al, 2001), technopolis centers (Pop, 2011); educational platforms as original systems for achieving, transferring and implementing knowledge (Papoutsidakis et al, 2008), communities of practice, especially family businesses (Fotea et al, 2012a; Fotea et al, 2012b; Wenger, 1998), and other kind of creative innovative centers, as start-ups, industrial \& scientific parks, business incubation, cloud business, integrative laboratories, etc (Christensen \& Schunn, 2005; Pop, Maties, 2011; Derry \& Fischer, 2005; (Nicolescu, 1997; Hugos \& Hulitzky, 2011; Warfield, 2007). Informergical knowledge cannot be considered a basic methodology of work, but it functions with specific synergistic synthesis methodologies, being more than a simply multi (pluri) disciplinary, or an inter(cross) disciplinary character but a transdisciplinary one, which generates new disciplines in a codisciplinary context, while the curricula is contextualized and flexible (Fortuin \& Bush, 2010).

The creativity centers are working for a sustainable development of an integrated and continuously integrative society, the synergistic correlations with other spheres of knowledge are improved, the major goals in the field of the new informergic society being focused on the products, technologies for satisfaction of client and 
market, as well. In order that one be considered to be involved the process of developing knowledge, one should balance the rationality in the knowledge of things (by doing) and the relationship to better understand the world (by being) (Nicolescu, 1996; Pop, 2011; Pop \& Maties, 2008).

In order that the education process report the necessary changes, the knowledge development process needs to undergo a paradigm shift by identification and acknowledgment of the major trends which brought forth mutations in the education purposes, thus leading to a re-evaluation of the curricula in an innovative and creative context (Langley et al, 1987; Carayannis \& Campbell, 2006).

\subsection{University and the new transdisciplinary perspective on knowledge}

As it was presented before, only informergy integrates rational knowledge of things with relational understanding of the world, thus achieving advanced knowledge requires the transdisciplinary methodology, which openly and flexibly integrates knowledge (McGregor \& Volckmann, 2010; Pop \& Maties, 2011). To fulfil the demands for high expertise to be achieved it is important to develop vocational educational training systems in the context of KBS/E (Chisholm, 1997; Pop, 2009; Aerts 2000). By integrating the much needed newly developed theoretical sequences (top-down perspective) and applied learning sequences (bottom-up perspective) individuals can acquire key competencies and upgrade their skills within an all-life learning process, which is continuous in nature (Pop \& Maties, 2011; Pop, 2009). The proposed objectives can be achieved by three complementary approaches through long-term persistent efforts: (1) raising the expertise as an advanced knowledge level; (2) implementing sustainable strategies as "all life learning" educational process, and (3) the knowledge triangle for creativity (Pop, 2009a). From the interaction of research, education and innovation the knowledge triangle is shaped into a key driver of the KBS/E.

The historic collaboration between academia and industry, which mainly relied on joint research projects funded by the industry is no longer enough with the advent of the global knowledge economy, strategic partnerships being a good replacement. Universities are designed to be in the front of the competitiveness of companies, universities and research centers. The research university for the KBS/E represents a vital hub of competences to help address challenges of social and economic nature, thus driving economic growth (Fuller, 2003). The transdisciplinarity methodology aims to challenge of bridging the industry-university-research centers making research universities appealing as business partners, with the proper structures for exceptional partnerships (Montaud, 2008; Sutz, 2000; Brennenraedts et al, 2006). In the context of the synergistic integration of the knowledge triangle for creativity, universities are considered the best natural home with a flexibility 
Pop, I. Gh., Fotea, I. S., Fotea, S. L. (2018)

Innovation networking, knowledge transdisciplinary spaces

and continuous adaptive process in the $\mathrm{KBS} / \mathrm{E}$, as a space with a permanent possible reconfiguration combining a high required degree with breadth profile competence in an integrated field of different disciplines, while having an in-depth knowledge of their expertise field (Nicolescu, 1997; Kaynak, 1996; Pop, 2011; Brennenraedts et al, 2006; Sutz, 2000; Carayannis, \& Campbell, 2006).

The presented opening sustainable perspective allows to implement the achieved knowledge in intelligent products, technologies and systems, while the transdisciplinary approach builds new paths to develop and incorporate an increasing number of ideas, thus improving the doing of things and living of life in a constantly changing environment, with new needs of a more complex world, putting pressure on improving and developing new technologies. The true informergic experts (engineers, managers, workers, or technicians) have a genuine interest and ability across a wide range of technologies, working beyond the boundaries of disciplines in a multiple disciplinary thinking perspective to distinguish and utilize the particular mix of technologies that offer most fitted solutions to the problems that emerge, able to promote alternative approaches (Pop \& Mătieş, 2011).

This new methodology is working to achieve the informergic knowledge process by teaching/learning, understanding and developing specific skills, based on an active-reactive understanding-learning process, which can appear intentional or spontaneous, thus allowing the control of information, questioning, integrating or even reconfiguring it (Nicolescu, 1996; Pop, 2011). A framework of models for dynamic systems can be developed, deriving from a real, natural model to a design one, with the inherent understanding of the best use of the models, with its vertically structural system levels in a balance between theory and practice, through the included middle approach of knowledge (Waks, 1997; Lupasco, 1987; Pop, 2009). In such a way is possible the formation of the specific experts with new skills in a permanent contextual adaptive changing at the contextual needs, learning, working in networking transdisciplinary spaces, to process integrated knowledge (Aerts, 2000; Pop, 2011).

Informergy represents a generative synergistic synthesis of Scientia, Techne and Praxis, with Scientia as a new educational transdisciplinary paradigm (the new epistemology), Techne, working as a reflexive way of the integrative design, the creative logic of the included middle, and Praxis, as a new economy of the intelligent products, through the mattergic embedded informaction, with a new socio-interactive system of thought, living and action, the new approach of ontology (Pop \& Mătieş, 2011). The common significant generative-synergistic space of the knowledge resulted here is a metacognitive space considered as an open transdisciplinary integrative system of the informergic knowledge, the 
conceptual and practical transdisciplinary space of knowledge (Brennenraedts et al, 2006). The companies, industries, research centers should work side by side with universities, cancelling the borders of knowledge, which generates a powerful economic growth and innovation engine, giving rise to new technologies at a extremely rapid pace, and transforming industries and changing the role of the university in a synergistic generative way (Arvanitis et al, 2005). This collaboration is functioning as a strategic top priority, to improve a climate for innovation, transforming the universities from „ivory towers" into a "global village" transdisciplinary pattern (McGregor \& Volckmann, 2010). Intellectual property (IP) as a top knowledge potential is a very important issue but it does not represent the highlight of industry-research centres-university relations (Fantana, 2016). When universities are involved in offering pragmatic solutions for the industry and do not view IP as a merely income source, the revenue stream can be higher and the advantages wider (Weber \& Bergan, 2005; Vajkai, 2002; Paavola et al, 2004). The true value in what does represent $R \& D$ (research and development) is often the tacit knowledge produced by it. Innovation is highly dependent on the way experts from university and industry can work together across multiple disciplines, like technology, engineering and design to name a few. It is necessary to encourage such transdisciplinary academic programs and to promote the involvement of industry and business, which take down traditional academic silos and impact the new ,global village” transdisciplinary culture and curriculum, and to transform the research university into a source of competence and problem-solving for society, accelerating innovation and helping to deliver solutions to important challenges of social nature (McGregor \& Volckmann, 2010; Montuori, 2006; Fortuin \& Bush, 2010; Paavola et al, 2004). In this sense, one needs to redefine the mission of the research university, the collaboration with industry should be linked to a reformulation of the role of the research in universities in the KBS/E (Castells, 2001). Transdisciplinary universities accept at large a model of higher education and research, the new vision should include producing the highly skilled workforce for a globally competitive economy. The university in the KBS/E should be viewed not only as a generator of ideas but also as a source of competence and knowledge that will bring advantages to the entire society (Tiffin \& Rajasingham, 2003; Vajkai, 2002; Fuller, 2003). In most cases partnerships of industry and university should generate funds for those involved, while some universities have done this in a nearly self-sustaining fashion, with every instance being influenced by the general interests, strengths and objectives among the partners (Montuori, 2006; Weber \& Bergan, 2005). The perspectives to integrate universities with industry, economy and research centers, are determined from the way the transdisciplinary framework is put in practice to integrate the knowledge triangle for creativity 
Pop, I. Gh., Fotea, I. S., Fotea, S. L. (2018)

Innovation networking, knowledge transdisciplinary spaces

(education, research and industry) to raise the expertise at an progressive knowledge level (as wisdom and skill achievement), and to implement sustainable strategies as "all life learning" educational process to assimilate contextually the synergistic messages that are transforming the data and information in advanced knowledge, (Pop, 2009a; Pop et al, 2015; Pop et al, 2017; Aerts, 2000) to realize the university of the age of supercomplexity (Barnet, 2000).

\section{Discussions and Conclusions}

The accomplishment of proposed objectives of the research is revealed, as original contributions, considering the informergy as a generative synergistic synthesis of Scientia, Techne and Praxis, through the mattergical embedded informaction, with a new socio-interactive system of thought, living and action, the new approach of ontology. The common significant generative-synergistic space of the knowledge configured is a metacognitive space as an open transdisciplinary integrative system of the informergical knowledge, not a simple working methodology, but working with specific synergistic synthesis methodologies, being more than a simply multi(pluri)disciplinary, or an inter(cross)disciplinary character but a transdisciplinary one, generating new disciplines in a codisciplinary context with flexible and contextual curricula. The all-life learning principle with its components, lifelong learning, life-wide learning and learning-for-life, allows the formation of the experts with new skills in a permanent contextual adaptive changing at the contextual needs, learning, working in technopolis centers, as networking transdisciplinary spaces, to processing integrated and integrative knowledge.

The presented opening sustainable perspectives allows to implement the achieved knowledge in intelligent products, technologies and systems, with new perspectives, incorporating more and more ideas to improve the way to do things and to live in the new context of ever-changing needs and willing of a complex and complicated world, when innovations and technologies should be improved and developed with the rapidly changing times. The transdisciplinary creativity centers are working for a sustainable development of an integrated and continuously integrative society, the mobile educational centers as platforms working as a networking teaching factory to achieve, transfer and implement informergic knowledge being a future configuration of the technopolis transdisciplinary knowledge spaces in the KBS/E. The mission of the research university should to be redefined to reconfigure the role of the research in universities linked with industry and economy in the $\mathrm{KBS} / \mathrm{E}$, as a ground-breaking knowledge networking, to produce the highly skilled workforce for a globally competitive economy. The 
Pop, I. Gh., Fotea, I. S., Fotea, S. L. (2018)

Innovation networking, knowledge transdisciplinary spaces

university in the KBS/E should be viewed not just as a generator of ideas but as a source of knowledge and competence that can benefit society.

\section{References}

1. Aerts D. (2000), Participating in the World: Research and Education in a Changing Society, in:Science, Technology and Social Change, The Orange Book of Einstein meets Magritte (eds. D.Aerts, S. Gutwirth, S. Smets and L. Van Langenhove), pp. 1-34, Dordrecht, Kluwer AcademicPublishers.

2. Aerts, D., (2001), Transdisciplinary and integrative sciences in sustainable development, in the Encyclopedia of Life Support Systems, Baldwin House, Aldates, Oxford;

3. Adamsson, N., (2007), Interdisciplinary integration in complex product development: managerial implications of embedding software in manufactured goods. Machine Design. Stockholm, KTH Royal Institute of Technology. Doctoral thesis.

4. Albert \& Lukas, 1999), Knowledge spaces: Theories, empirical research, applications. Mahwah, NJ: Lawrence Erlbaum Associates

5. Alptekin, S.E., (1995), "Smart Products - A Tool for Mechatronics Education", Proceedings of International Conference on Recent Advances in Mechatronics ICRAM'95, 14-16, Volume I, pp: 288-292.

6. Alptekin, S.E.,, Pouraghabagher, R., McQuaid, P., Waldorf, D., (2001), Teaching Factory, Proceedings of the 2001 American Society for Engineering Education Annual Conference \& Exposition, American Society for Engineering Education;

7. Arvanitis, S., Sydow, N., Woerter, M., (2005), Is There Any Impact of UniversityIndustry Knowledge Transfer of the Performance of Private Enterprises? An Empirical Analysis Based on Swiss Firm Data, Zurich, Switzerland: Swiss Institute for Business Cycle Research.

8. Barnet, R., (2000), Realizing the University in the Age of Supercomplexity, The Society for Research into Higher Education \& Open University Press.

9. Bernstein, J.H., (2015), Transdisciplinarity: A Review of Its Origins, Development, and Current Issues Journal of Research Practice Volume 11, Issue 1, Article R1, 2015 Review:

10. Brandt, P.; Ernst, A.; Gralla, F.; Luedritz, C.; Lang, D.J.; Newig, J.; Reinert, F.; Abson, H.;von Wehrden, H.A, review of transdisciplinary research in sustainability science, (2013). Ecol. Econ. 2013, 92, 1-15.

11. Brazell, J., Elliot, H., Vanston, J., (2005), Mechatronics: Integrating Technology, Knowledge \& Skills. http://system.tstc.edu/forecasting/techbriefs/mechatronics.asp.

12. Brennenraedts, R.M., Bekkers, R., Verspagen, B., (2006), The different channels of university-industry knowledge transfer: Empirical evidence from Biomedical Engineering, Eindhoven, the Netherlands, Eindhoven Centre for Innovation Studies.

13. Brown, J. S., Duguid, P., (1991), "Organizational Learning and Communities-ofPractice; Toward a Unified View of Working, Learning and Innovation," Organization Science 2, No. 1, pp. 40-57

Studia Universitatis "Vasile Goldis" Arad. Economics Series Vol 28 Issue 2/2018 ISSN: 1584-2339; (online) ISSN: 2285 - 3065

Web: publicatii.uvvg.ro/index.php/studiaeconomia. Pages $86-106$ 
Pop, I. Gh., Fotea, I. S., Fotea, S. L. (2018)

Innovation networking, knowledge transdisciplinary spaces

14. Browning, T. R., Deyst, J. J. Eppinger, S. D., Whitney, D. E., (2002), Adding value in product development by creating information and reducing risk. IEEE Transactions on Engineering Management, vol. 49(4), pp.443-445.

15. Buckley, F. J., (2000), Team Teaching: What, Why, and How? London: Sage Publications, Inc.

16. Carayannis, E.G. \& Campbell, D.F.J. (2006). Knowledge Creation, Diffusion, and Use in Innovation Networks and Knowledge Clusters: A Comparative Systems Approach across the United States, Europe, and Asia. Praeger

17. Carryer, E., (1996), "Smart Products", Presentation at Preparing the Leaders for Mechatronics Education Workshop, Cal Poly, June 1995. Frontiers in Education Conference, 1996, Proceedings of 26th Annual Conference, Volume 2, Issue , 6-9 Nov. pp. $975-979$;

18. Castells, M., (2001), Universities as dynamic systems of contradictory functions. In J. Muller, N. Cloete and S. Badat (eds). Challenge of globalization. South African Debates with Manuel Castells, pp. 206-224.

19. Chisholm, L., (1997), Initial Transitions between Education, Training and Employment in Learning Society, International Bulletin of Youth Research, vol. 15, 1, pp. 6-16);

20. Cook, S.D.N., Brown, J. S., (1999). "Bridging epistemologies: the generative dance between organizational knowledge and organizational knowing", Organization Science, 10(4), pp. 381-400.

21. Covey, R., S., 2004, The 7 Habits of Highly Effective People: Powerful Lessons in Personal Change, Paperback - November 9, 2004, New York Free Press.

22. Christensen, B. T., Schunn, C. D., (2005). Spontaneous access and analogical incubation effects. Creativity Research Journal, 17(2), pp. 207-220.

23. Derry, S.J., Fischer, G. (2005), Toward a Model and Theory for Transdisciplinary Graduate Education, AERA Annual Meeting 2005, Symposium "Sociotechnical Design for Lifelong Learning: A Crucial Role for Graduate Education” April, pp. 1-28

24. Doignon, J-P., Falmagne, J-C., (1999), Knowledge Spaces. Berlin: Springer, 1999.

25. Dominik, J.; Loizeau, J.L.; Thomas, R.L. Bridging the gaps between environmental engineering and environmental science education. Int. J. Sustain. High. Educ. 2003, 4, 17-24.

26. Düntsch, I., Gediga, G., (1995), Skills and Knowledge Structures. British Journal of Mathematical and Statistical Psychology, vol. 48, pp. 9-27.

27. Ertas, A., (2010), Transdisciplinarity: Design, Process and Sustainability. Transdisciplinary Journal of Engineering and Science. Vol. 1, No: 1, pp. 30-48.

28. Falkenberg, K.F., (2016), Circular Economy Model Key to Boosting European Economy. 2014. Available online: https://www.theparliamentmagazine.eu/articles/opinion/circular-economy-model-keyboosting-european-economy (accessed on 10 October 2016).

29. Fantana, R.S, (2016), Dimensions of expert report complexity in intellectual /industrial property. Case study, Perspectives of Business Law Journal, Volume 5, Issue 1, November 2016, 147-160). 
Pop, I. Gh., Fotea, I. S., Fotea, S. L. (2018)

Innovation networking, knowledge transdisciplinary spaces

30. Fischer, G., (2005), "From Reflective Practitioners to Reflective Communities, Proceedings of the HCI International Conference (HCII)”, Las Vegas, July 2005, (published on CD).

31. Fortuin, I.K.P.J., Bush, S.R., (2010), Educating students to cross boundaries between disciplines and cultures and between theory and practice, International Journal of Sustainability in Higher Education, Vol. 11 (1), pp. 19-35, Emerald Group Publishing Limited)

32. Fotea, I., Pop, G.I., Vaduva, S., Fotea, S., (2012a), A transdisciplinary Approach to Business Education throughout Family Firms as Community of Practice, The $8^{\text {th }}$ Balkan Region Conference on Engineering Education \& $4^{\text {th }}$ International Conference on Engineering \& Business Education, pg. G159-165, 17-21 October, 2012, Lucian Blaga University of Sibiu, Romania.

33. Fotea, I., Fotea, S., Vaduva, S., Pop, G.I., (2012b), Fostering Entrepreneurial Learning in Family Business throughout Family Firms as Community of Practice, ApproachCase Study of Romanian Family Business, Economia Marche, Journal of Applied Economics, Vol. XXXI, No. 2, Nov. 2012).

34. Fuller, S., 2003), The University: A social technology for producing universal knowledge, Technology in Society vol. 25, pp 217-234.

35. Gibbons, M., Limoges, C., Nowotny, H., Schwartzman, S., Scott, P., Trow, M., (1994), The New Production of Knowledge - The Dynamics of Science and Research in Contemporary Societies, Sage, London.

36. Gitt, W., (1997), In the Beginning Was Information, Christliche Literatur-Verbeitung e.V. Postfach, Bielefeld.

37. Gomes, J.F., de Weerd-Nederhof, P.C., Pearson, A. \& Cunha, M.P. (2003). 'Is more always better? An exploration of the differential effects of functional integration on performance in new product development.' Technovation 23(3), pp. 185-192.

38. Hall, E.T., (1959), The Silent Language, Fawcett Publications, Inc, Greenwich, (Le langage silencieux, Seuil, 1984).

39. Hakkarainen, K., Palonen, T., Paavola, S., \& Lehtinen, E., (2004), Communities of networked expertise: Professional and educational perspectives. Pergamon Press.

40. Harashima, F., Tomizuka, M. and Fukuda, T., (1996), Mechatronics - "What Is It, Why, and How?" An Editorial", IEEE/ASME Transactions on Mechatronics, Vol. 1 (1), pp. 14

41. Hargreaves, A., (2003), Teaching in the Knowledge Society: Education in the Age of Insecurity, Open University Press.

42. Hildreth, P., Kimble, C., Wright, P., (2000), "Communities of Practice in the Distributed International Environment," Journal of Knowledge Management 4, No. 1, 27-38.

43. Hildreth, P., M., Kimble, C., 2004, Knowledge Networks:Innovation through Communities of Practice, Idea Group Inc (IGI), pp. 330-335

44. Hugos, M., Hulitzky, D., (2011), Business in the Cloud: What every business needs to know about Cloud-Computing, John Wiley \& Sons Inc., Hoboken, New Jersey

DE GRUYTER OPEN
Studia Universitatis “Vasile Goldis" Arad. Economics Series Vol 28 Issue 2/2018 ISSN: 1584-2339; (online) ISSN: 2285 - 3065

Web: publicatii.uvvg.ro/index.php/studiaeconomia. Pages $86-106$ 
Pop, I. Gh., Fotea, I. S., Fotea, S. L. (2018)

Innovation networking, knowledge transdisciplinary spaces

45. Jack, H., Sterian, A., (2002), Control with Embedded Computers and Programmable Logic Controllers. The Mechatronics Handbook, CRC Press

46. Jashapara A., (2011), Knowledge Management, an Integrated Approach, Pearson Education Limited, Edinburgh Gate Harlow Essex CM20 2JE, England

47. Kaynak, O., (1996), A new perspective on engineering education in mechatronics age, Proceedings of FIE 1996 Conference, Session 8b4: Mechatronics Education, vol.2, pp.970- 974.

48. Lamancusa, J., Jorgensen, J., Zayas-Castro, J., (1997), The Learning Factory - A New Approach to Integrating Design and Manufacturing into the Engineering Curriculum, Journal of Engineering Education, April, Vol. 86, No. 2, pp. 103-112.

49. Langley, P., Simon, H.A., Bradshaw, G.L., Zytkow, J.M. (1987), Scientific Discovery. Computational Explorations of the Creative Processes, Cambridge, Massachusetts and London: MIT Press.

50. Leonard, D., Sensiper, S., (1998), "The role of tacit knowledge in group innovation." California Management Review, vol. 40(3), pp. 112-132.

51. Lupasco, S., (1987), Le principe d'antagonisme et la logique de l'énergie Prolégomènes à une science de la contradiction, Hermann \& Cie. Colloque „Actualités scientifiques et industrielles", no. 1133, Paris, 1951; 2nd ed., Le Rocher, Monaco. "Transdisciplinarité" Series, 2002

52. Max Neef, M.A., (2005), Foundations of transdisciplinarity, Ecological Economics 53, pp. $5-16$.

53. McGregor, S.L.M., Volckmann, R., (2010), Transdisciplinarity in Higher Education, The Path of Arizona State University, Integral Leadership Review, vol.X, 3

54. Montaud, A., (2008), Le monde de mecatroniques, Artema Mechatronics Infos 2008, pp. 1-2

55. Montuori, A., 2006, The quest for a new education: From oppositional identities to creative inquiry. ReVision, vol. 28 (3), pp. 4-20).

56. Mieg, H.A., (1996), Managing the interfaces between science, industry, and education, in UNESCO (ed), World Congress of Engineering Educators and Industry Leaders, UNESCO, Paris, vol. 1, pp.529-533

57. Noe, R., 2008, Employee Training and Development. 4th Edn., Mcgraw-Hill/Irwin, ISBN: 0-07-340490-X, pp: 552.

58. Novak, J.D. (1998), Learning, creating and using knowledge: Concept maps as facilitative tools in schools and corporations. Mahwah: Lawrence Erlbaum.

59. Nicolescu, B., (1996), La transdisciplinarité, manifeste, Le Rocher, Monaco, coll. "Transdisciplinarité"; English translation by Karen-Claire Voss: Manifesto of Transdisciplinarity, State University of New York (SUNY) Press, New York, 2002 (English translation: Watersign Press, Lexington, USA ; Ed. Polirom, Iaşi, 1999).

60. Nicolescu, B. (1997). The transdisciplinary evolution of the university condition for sustainable development. http://perso.club-internet.fr/nicol/ciret/bulletin/b12/b12c8.htm

61. Nicolescu, B., (2006), Transdisciplinarity - Past, Present and Future, în Haverkort B., Reijntjes C., Moving Worldviews - Reshaping Sciences, Policies and Practices for Endogenous Sustainable Development, COMPAS Editions, Holland, pp 142-166. 
62. Nicolescu, B., (2008), Transdisciplinarity - Theory and Practice (Ed.), Hampton Press, Cresskill, NJ, USA.

63. Nicolini, D., Gherardi, S. and Yanow, D. (eds.) (2003) Knowing in Organizations: A Practice-Based Approach. Armonk, NY: M.E. Sharpe.

64. Nonaka, I., Takeuchi, H., (1994), “A Dynamic Theory of Organizational Knowledge Creation," Organizational Science, vol. 5, No. 1, pp. 14-37.

65. Paavola, S., Lipponen, L., Hakkaraininen, K. (2004), Models of innovative knowledge communities and three metaphors of learning. Review of Educational Research, vol. 74(4), pp. 557-576.

66. Papoutsidakis, M.G., Andreou, I.K., Chamilotoris, G.E., (2008), Challenging educational platforms in mechatronics: learning framework and practice, Proceedings of the 5th WSEAS/IASME International Conference on Engineering Education, pp. 121126.

67. Palmer, S.E., (1978), Fundamental aspects of cognitive representation, in E. Rosch \& B.B. Lloyd (eds.), Cognition and Categorization, Erlbaum, Hillsdale, pp. 259-303

68. Petts, J., Owens, S., Bulkeley, H., (2008), Crossing boundaries: interdisciplinarity in context of urban environments, Geoforum 39. pp. 593-601.

69. Polanyi, M., (1997), "The Tacit Dimension,"Knowledge in Organizations, L. Prusak, Editor, Butterworth-Heinemann, Woburn, MA.

70. Pop, I. G., Mătieş, V., (2008a), A Transdisciplinary Approach to Knowledge in Mechatronical Education, 7th France-Japan and 5th Europe-Asia Mechatronics Congress, Anecy, May 21-23, pp. 195-198.

71. Pop, I.G., (2009a), Creativity as a Reflexive Transdisciplinary Language in the Mechatronical Knowledge, "Problems of Education in the 21st Century", Lithuania, vol.13 (13), pp. 94-102, may, 2009; 11, SMC “Scientia Educologica”, Lithuania, ISSN 1822-7864;

72. Pop, I.G., (2009b), Considerations about the Transdisciplinary Knowledge Search Window in Mechatronical Education, The $5^{\text {th }}$ Balkan Region Conference on Engineering Education \& $2^{\text {nd }}$ International Conference on Engineering and Business Education, October $15^{\text {th }}-17^{\text {th }}$, pp. 159-165, University Lucian Blaga, Sibiu, Romania.

73. Pop, I.G., Maties, V., (2011), Transdisciplinary Approach of the Mechatronics in the Knowledge Based Society, in Mechatronics, Intech Open Access Publisher, Rijeka.

74. Pop, I.G., (2011), Thesis, Considerations on the Transdisciplinary Approach of the Mechatronics in the Knowledge Based Society, Technical University, Cluj-Napoca, 2011.

75. Pop, I.G.; Talpos, M.F.; Prisac, I. (2015), Transdisciplinary Approach on the Advanced Sustainable Knowledge Integration, Balkan Region Conference on Engineering and Business Education. In Proceedings of the IETEC-BRCEBE Conference, Sibiu, Romania, 1-2 November 2015; Volume 1; ISSN (Online de Gruyter) 2391-8160. doi:10.1515/cplbu-2015-0025.

76. Pop, I.G., Văduva S., Talpoș M.F., (2017), Energetic Sustainability and the Environment: A Transdisciplinary, Economic-Ecological Approach Sustainability 2017, 9(6), 873; doi:10.3390/su9060873 
Pop, I. Gh., Fotea, I. S., Fotea, S. L. (2018)

Innovation networking, knowledge transdisciplinary spaces

77. Pop, N.Al.; Pelau, C. (2017): Correlations within the EFQM Business Excellence Model by Applying a Factor Analysis, in: Amfiteatru Economic, nr. 44/ 2017, pg. 28-40 (ISSN- 1582 - 9146)

78. Quinsee, S. \& Hurst, J. (2005). Bluring Bounderies? Support Students and Staff within an Online Learning Environment? Turkish Online Journal of Distance Education, Vol. 6, Nr. 1, 52-59.

79. Reason, P., (1998), Political, Epistemological, Ecological and Spiritual Dimensions of Participation, Culture and Organization, Vol.4, 2, pg.147-167.

80. Roux, D. J., Rogers, K. H., Biggs, H. C., Ashton, P. J., Sergean, A., 2006, Bridging the science-management divide: moving from unidirectional knowledge transfer to knowledge interfacing and sharing, Ecology and Society,V11 No 1: 4.

81. Scholz, R.W., Mieg, H.A., Oswald, J.E., (2000), Transdisciplinarity in Groundwater Management-towards Mutual Learning of Science and Society, Water, Air and Soil Pollution, 123, pp. 477-487.

82. Šlaus, I., (2003), Political Significance of Knowledge in Southeast Europe, Croat. Med. Journal; vol.4, pp. 3-19.

83. Strathern, M., (2007), „Knowledge Identities” in Ronald Barnett, Roberto di Napoli (eds), Changing Identities in Higher Education. Voicing Perspectives. Routlidge. London. New York.

84. Sutz, J., K.E., (2000), The role of universities in knowledge production, Himalayan Journal of Sciences, 3(5), pp. 53-56.

85. Tiffin, J., Rajasingham, L., 2003), The Global Virtual University, London: Routledge Falmer);

86. Tundrea, E., (2009), Contributions to the Modelling and the Use of the Software Product Lines, Ph.D. Thesis, UPT, seria10, nr. 11, Editura Politehnica, Timisoara, Romania.

87. Vajkai, A., (2002), „The role of Universities in Buildings the Information Societies, in University and Society. Curent problems of regional co-operation, Proceedings of the conference held at the University of Pecs.

88. Waks, S. (1997), Lateral thinking and technology education. Journal of Science Education and Technology, vol. 6(4), pp. 245-255.

89. Warfield, J. N., (2007), Enterprise Information Systems, Systems science serves enterprise integration: a tutorial, Taylor \& Francis, Inc., Vol.1, (2), pp. 235-254.

90. Weber, L., Bergan, S., (eds), 2005), The public responsibility for higher education and research. Council of Europe higher education series no. 2, Strassbourg, Council of Europe);

91. Wenger, E., Snyder, B., (2000), "Communities of Practice: The Organizational Frontier," Harvard Business Review vol. 78, No. 1, pp. 139-145.

92. Zeleny, M., (1987), "Management Support Systems: Towards Integrated Knowledge Management", Human Systems Management, vol. 7, 1, pp. 59-70. 